\title{
Analysis of the K-ras/B-raf/Erk signal cascade, p53 and CMAP as markers for tumor progression in colorectal cancer patients
}

\author{
MILKA GEORGIEVA $^{1,4}$, MARIA KRASTEVA ${ }^{2}$, ELKA ANGELOVA $^{3}$, KRASSIMIR RALCHEV $^{3}$, \\ VALENTIN DIMITROV ${ }^{3}$, STANISLAV BOZHIMIROV ${ }^{2}$, ELENA GEORGIEVA ${ }^{2}$ and MARTIN R. BERGER ${ }^{4}$ \\ ${ }^{1}$ Laboratory of Molecular Diagnostics, National Oncology Centre, 6 Plovdivsko Pole Str., 1756 Sofia; \\ ${ }^{2}$ Institute of Genetics, Bulgarian Academy of Sciences, Department of Molecular Genetics, Plovdivsko Chausse $13 \mathrm{klm}$, \\ 1113 Sofia; ${ }^{3}$ Surgical Clinic, National Oncological Centre, 6 Plovdivsko Pole Str., 1756 Sofia, Bulgaria; ${ }^{4}$ Toxicology and \\ Chemotherapy Unit, German Cancer Research Center, Im Neuenheimer Feld 280, 69120 Heidelberg, Germany
}

Received November 15, 2007; Accepted January 30, 2008

\begin{abstract}
Colorectal cancer patients may succumb to their disease because of local recurrence or formation of metastasis. To develop a prognostic tool for these fatal types of progression, 23 patients with colorectal carcinoma were included in this study for the detection at the time of surgery of the incidence of K-ras, B-raf and p53 mutations, the phosphorylation status of Erk and the expression of cystatin-like metastasis-associated protein (CMAP) in tumor, mucosa and liver samples. Polymerase chain reaction-restriction fragment length polymorphism and PCR-SSCP were used to detect the respective mutations. The results of these assays were complemented by sequencing the K-ras, B-raf and p53 mutations. A multiplex RT-PCR assay was used to detect the CMAP mRNA levels and the phosphorylation status of Erk in tumor samples was assessed by Western blot using a phospho-specific Erk antibody. The carcinomas were classified as stages T4 (70\%), T3 (17\%), T2 (9\%) and T1 (4\%) and thus represent a group of advanced colorectal carcinomas. The carcinomas ( 8 out of $23,39.1 \%$ ) were mutated in K-ras codons 12 or 13 and two patients had a B-raf (V599) mutation in their tumor. Of 22 tumors, $11(50 \%)$ were positive for pErk, indicating the activation of the RAS/RAF/ERK signaling pathway. Of the 23 tumors, 13 (65.5\%) showed an increased CMAP RNA level. Notably, 10 of these 13 patients have already died and two developed liver metastasis. Mutations in p53 were found in only 6 patients (26\%), with 6 being detected in carcinoma, 1 in mucosa and 1 in liver
\end{abstract}

Correspondence to: Professor Martin R. Berger, Toxicology and Chemotherapy Unit, German Cancer Research Center, Im Neuenheimer Feld 280, 69120 Heidelberg, Germany

E-mail: m.berger@dkfz.de

Key words: colorectal cancer, K-ras mutations, B-raf mutations, ERK activation, p53 mutation, cystatin-like metastasis-associated protein expression tissue. These alterations were classified as non-sense $(n=1)$, mis-sense $(n=2)$ and frame-shift mutations $(n=1)$ as well as intron polymorphisms $(n=5)$. There was a significant correlation between Erk activation and K-ras codon 12 mutation ( $\mathrm{p}=0.016$ ), but not between K-ras codon 13 or B-raf mutations and Erk activation. Furthermore, there was a significant correlation of each positive marker with tumor stage $(\mathrm{p}=0.001)$.

\section{Introduction}

A significant amount of research in the past several years suggests that a number of prognostic markers may be useful in defining the individual risk of colorectal cancer patients after surgery and in determining which patients may benefit the most from adjuvant chemotherapy $(1,2)$. Therefore, it is critical to investigate molecular markers that will identify more aggressive colon cancer phenotypes to tailor patient therapy accordingly.

Colorectal cancers develop as a result of different combinations of genetic alterations, epigenetic changes and post-translational modifications. Such molecular alterations affect oncogenes, tumor-suppressor genes and the genes encoding the enzymes critical for mismatch excision repair (3). Phosphorylation plays a key role in the post-translational modification of proteins that regulate their function and activity (4).

The RAS/RAF/MEK/ERK/MAP signal transduction pathway is a conserved RAS-activated protein kinase cascade that regulates cell growth, proliferation and differentiation in response to growth factors, cytokines and hormones (5). The constitutive activation of this pathway is common to numerous cancers. Of human cancers, $\sim 15 \%$ have activating ras mutations (6) and mutations in B-raf were identified in a large-scale screen for genes mutated in human cancer (7). The most frequently activated positions of the K-ras gene in human tumors have been found to be codons 12 and 13. These activating mutations produce an alteration in the transduction of signals in the RAS pathway and ultimately lead to increased mitogenic signaling. The frequency of K-ras codon 12 and 13 
mutations in colorectal carcinoma has been reported to vary between 20 and $50 \%$. In addition, K-ras mutations have been reported to occur early in colorectal tumorigenesis, but their role in tumor initiation and development is still unclear. Mutations in K-ras have been found to occur frequently in histologically normal mucosa adjacent to the tumors of patients with K-Ras mutation-positive colorectal carcinoma. This suggests that K-ras mutations may be used as a biomarker for early colorectal cancer detection. Mutations involving the oncogene K-ras in colorectal neoplasms have been related to tumor aggressiveness in some series, but not in others. Their role in predicting the survival of CRC patients is still inconclusive.

The somatic mutations of B-raf are associated with $60 \%$ of malignant melanomas and occur with moderate to high frequency in colorectal (8), ovarian (9) and papillary thyroid carcinomas (10), indicating activating mutations of B-raf as critical promoters of malignancy. Significantly, B-raf and $\mathrm{K}$-ras mutations are restricted to the same tumor types, usually in a mutually exclusive fashion, suggesting that these genes are members of the same oncogenic signaling pathway and that RAS acts to activate B-RAF in these tumors.

Of the mutations in B-raf, $290 \%$ are $\mathrm{T}-\mathrm{A}$ transversions at the nucleotide 1796 (T1796A), leading to a substitution of glutamic acid for valine at amino acid 599 (V599E) in the activation segment. The V599E mutation is thought to mimic phosphorylation by inserting a negatively charged residue adjacent to the phosphorylation site at $\mathrm{T} 598$, rendering B-Raf constitutively active. The mutation of B-raf at V599E leads to constitutive Erk activation and this is known to have a profound influence on the G1/S transition of the cell cycle through the regulation of the expression of a number of cell cycle proteins. This has been taken as evidence that the inappropriate regulation of downstream Erks is a major contributing factor in the development of malignant melanomas and colon cancer (7).

The RAS/RAF/MEK/ERK/MAP kinase cascade is an essential component of intracellular signaling from activated cell surface receptors to transcription factors in the cell nucleus. The activation of the small GTPase protein RAS recruits RAF to the plasma membrane, where it becomes activated. Activated RAF proteins directly phosphorylate and activate downstream kinase MEK, which in turn phosphorylates ERK, thereby activating it. Activated ERK phosphorylates many cytoplasmic target proteins, such as Rsk and several nuclear transcription factors, including Elk-1. In the case of the stimulation of EGF and PDGF, the activation of ERK is an absolute requirement for cell proliferation. The mutation of B-raf and concomitant ERK activation may influence the progression of malignancy. An active ERK may allow the tumor to develop its own angiogenic support system by inducing the expression of VEGF (11). The activation of ERK in tumors allows for the evasion of apoptosis by inducing cell survival (12). Active ERKs may influence cell migration and metastasis through influencing the expression of integrins (13).

On the other hand, $>50 \%$ of colorectal cancers display p53 mutations. It has been shown that the p53 protein arrests the cell cycle at the $\mathrm{G} 1$ phase and induces apoptosis in response to DNA damage. Therefore, p53 alterations are frequently reported in relation to the prognosis and response to treatment. The presumed relation between the aberrant p53 expression, prognosis and angiogenesis in primary colorectal cancer has been extensively studied although with contradicting results. Basically, alterations in p53 can be analyzed by mutation analysis and immunohistochemistry. Mutations in the TP53 gene can either result in the production of a stable or truncated p53 protein. It has been shown, that simultaneous mutations in K-ras and TP53 are indicative of a worse prognosis in sporadic colorectal cancer (14).

A novel metastasis-associated gene was identified with a differential display system in murine carcinoma cells, showing a high rate of metastasis to the liver. A human homologue was also identified by using a PCR-based strategy (15). The protein encoded by this gene was named cystatin-like metastasisassociated protein (CMAP) and showed a 22.1-28.1\% homology to the human family II cystatins. The expression of CMAP in tumor tissue was found to be markedly up-regulated compared with that of the corresponding normal tissue, thus suggesting the association of CMAP expression with the malignant properties of human CRC. A sharp correlation between an increased human CMAP expression status and a high frequency of liver metastasis was statistically confirmed by both univariate and multivariate analysis (16). It is suggested that CMAP indicates a new approach to the diagnosis and/or prevention of liver metastasis of human cancer.

The aim of this study was to determine the incidence of various potential markers for prognosis (K-ras, B-raf and p53 mutations, the phosphorylation status of ERK and the expression of CMAP) in different tissues (tumor, mucosa and liver) from patients with colon cancer at the time of their primary surgery. It was hoped that the combination of these parameters may aid in assessing the cancers regarding early recurrence, potential metastasis formation, and response to chemotherapy and preoperative radiotherapy. If so, this combination could be used for developing a diagnostic and prognostic tool for cancer recurrence and the prediction of the potential development of liver metastasis after surgery.

\section{Materials and methods}

Patients, tissue source and storage. Twenty-three patients undergoing elective surgery for colorectal cancer at the National Oncological Centre, Sofia, Bulgaria were included in this study after giving their informed consent. Samples were collected between October and December 2001 from primary tumor, mucosa and liver (right lobe). The mucosa and liver specimens were clinically free of metastasis. All tissues were immediately placed in cryovials, shock-frozen in liquid nitrogen and stored at $-80^{\circ} \mathrm{C}$ until further processing.

RNA/DNA/protein isolation. A combined RNA/DNA extraction was performed using a Qiagen RNA/DNA kit (Qiagen, Hilden, Germany) according to the manufacturer's recommendations. In brief, tissue samples weighing about $100 \mathrm{mg}$ were homogenized in lysis buffer using a homogenizer. The amount of isolated nucleic acid was determined spectrophotometrically.

Protein isolation was performed as follows: tissue samples weighing about $30 \mathrm{mg}$ were homogenized in lysis buffer with DTT (200 mM final concentration) and complete protease 
Table I. Primer sequences.

\begin{tabular}{|c|c|}
\hline Primer & Sequence \\
\hline KRAS $5^{\prime}$ & 5'-ACT GAA TAT AAA CTT GTG GTC CAT GGA GCT-3' \\
\hline KRAS 3' outer & 5'-TTA TCT GTA TCA AAG AAT GGT CCT GCA CCA-3' \\
\hline KRAS 3 ' inner & 5'-GGA TGG TCC TCC ACC AGT AAT ATG GAT ATTA-3' \\
\hline RAS-Sequ & 5'-ACC TCT ATT GTT GGA TCA TA-3' \\
\hline BRAF 5' & 5'-TCA TAA TGC TTG CTC TGA TAG GA-3' \\
\hline BRAF 3 ' outer & 5'-GGC CAA AAA TTT AAT CAG TGG A-3' \\
\hline BRAF 3' inner & 5'-AGT GGA AAA ATA GCC TCA A-3' \\
\hline BRAF & 5'-ССТ TTA CTT ACT ACA CCT CAG-3' \\
\hline CMAP 5' sense & 5'-AAG TTC AAC AAC TGC ACG AA-3' \\
\hline CMAP 3' antisense & 5'-CAG CTC AGA GTC TGC TTC AA-3' \\
\hline GAPDH $5^{\prime}$ sense & 5'-ACC ACA GTC CAT GCC ATC AC-3' \\
\hline GAPDH 3 ' antisense & 5'-TCC ACC ACC CTG TTG CTG TA-3' \\
\hline \multicolumn{2}{|c|}{ p53 exons $4,5,6,7,8$ and 9} \\
\hline p534F & 5'-TGC ACC AGC AGC TCC TAC AC-3' \\
\hline p534R & 5'-CAT GGA AGC CAG CCC CTC AG-3' \\
\hline p535F & 5'-GTG CCC TGA CTT TCA ACT CTG-3' \\
\hline p535R & 5'-GGG CAA CCA GCC CTG TCG-3' \\
\hline p536F & 5'-CGT CTA GAA TTC CTC ACT GAT TGC TC-3' \\
\hline p536R & 5'-CGG TCG ACA GTT GCA AAC A-3' \\
\hline p537F & 5'-CGT CTA GAG GCC TGT GTT GTC TCC-3' \\
\hline p537R & 5'-CGG TCG ACG GTG GCA AGT GGC TCC-3' \\
\hline p538F & 5'-ATT TCC TTA CTG CCT CTT GCT TC-3' \\
\hline p538R & 5'-CTT GGT CTC CTC CAC CGC-3' \\
\hline p539F & 5'-GCC TCA GAT TCA CTT TTA TCA CC-3' \\
\hline p539R & 5'-GAC TGG AAA CTT TCC ACT TGA TAA G-3' \\
\hline
\end{tabular}

inhibitor cocktail (Roche, Mannheim, Germany) using a homogenizer. The amount of protein was determined using the BCA protein assay reagent from Pierce (Rockford, IL, USA).

The detection of K-Ras mutations and DNA sequencing. The detection of K-Ras mutations in codons 12 and 13 was performed by PCR-RFLP as previously described (17). In brief, DNA was amplified in the first PCR (30 cycles), using primers Ras A and -B (Table I) which generated an amplicon of $166 \mathrm{bp}$. The Ras A sense primer introduced a restriction site for the enzymes BstXI and XcmI into the wild-type sequence. Subsequently, in the first digest, BstXI and XcmI cut the amplicon only if the first two bases of codons 12 or 13 were wild-type. The first digest was used as a template for the second PCR with primers Ras A and C, the latter creating a restriction site in both, with mutant and wild-type amplicons for the enzymes BstXI and XcmI. The resulting amplicon was $152 \mathrm{bp}$ and underwent a second restriction. An aliquot of the second digest was run on a polyacrylamide gel, stained with ethidium bromide and analysed under UV-light using a video-densitometer. Amplicons of the mutated DNA were cut only once into fragments of 134 and $18 \mathrm{bp}$, whereas ampli- cons of the wild-type DNA were cut twice into fragments of 106, 28 and $18 \mathrm{bp}$.

DNA sequencing was performed as previously described (17). Briefly, bands with a length of $134 \mathrm{bp}$, indicating the mutated DNA, were excised from 3\% agarose gels. After purification (QiaQuick Gel Extraction Kit, Qiagen, Hilden, Germany) the DNA was sequenced with the Big Dye terminator cycle sequencing ready reaction kit (ABI PRISM, Weiterstadt, Germany) using primer Ras (Table I). The product of $110 \mathrm{bp}$ was run on an ABI 310 Sequencer (ABI PRISM).

The detection of B-raf mutations. The detection of B-raf mutations at codon 599 was performed by enriched two-step PCR with intermittent restriction digestion to eliminate normal alleles selectively, thus enriching mutant alleles. DNA was amplified in the first PCR (35 cycles), using primers B-Raf A and B (Table I) which generated an amplicon of $179 \mathrm{bp}$. An intermittent restriction digestion of an aliquot of the first PCR product was carried out with restrictase TspRI and an aliquot of this reaction was used as a template for the second round PCR, performed with primers B-Raf A and C, which generated a fragment of $166 \mathrm{bp}$. Amplicons of mutated DNA 
Table II. Patient and tumor characteristics specified by gender.

\begin{tabular}{|c|c|c|c|}
\hline No. of patients & $\begin{array}{c}\text { Females, n }(\%) \\
9\end{array}$ & $\begin{array}{c}\text { Males, n }(\%) \\
14\end{array}$ & $\begin{array}{c}\text { Total, n }(\%) \\
23\end{array}$ \\
\hline Mean age in years & 61.5 & 63.2 & 62.3 \\
\hline \multicolumn{4}{|l|}{ Tumor localisation } \\
\hline Coecum & 0 & 0 & 0 \\
\hline Ascending colon & $1(4.30)$ & $2(8.70)$ & $3(13.0)$ \\
\hline Transverse colon & 0 & $1(4.30)$ & $1(4.30)$ \\
\hline Descending colon & 0 & $1(4.30)$ & $1(4.30)$ \\
\hline Sigmoid & $1(4.30)$ & $2(8.70)$ & $3(13.0)$ \\
\hline Rectum & $7(30.4)$ & $8(34.8)$ & $15(65.1)$ \\
\hline \multicolumn{4}{|l|}{ TNM classification } \\
\hline $\mathrm{T} 1$ & 0 & $1(4.30)$ & $1(4.30)$ \\
\hline $\mathrm{T} 2$ & $2(8.70)$ & 0 & $2(8.70)$ \\
\hline $\mathrm{T} 3$ & $1(4.30)$ & $3(13.0)$ & $4(17.4)$ \\
\hline $\mathrm{T} 4$ & $6(26.0)$ & $10(43.5)$ & $16(69.6)$ \\
\hline NO & $7(30.4)$ & $9(39.1)$ & $16(69.6)$ \\
\hline N1 & 0 & $4(17.4)$ & $4(17.4)$ \\
\hline $\mathrm{N} 2$ & $2(8.70)$ & $1(4.30)$ & $3(13.0)$ \\
\hline MO & $9(39.1)$ & $12(52.2)$ & $21(91.3)$ \\
\hline M1 & $1(4.30)$ & $1(4.30)$ & $2(8.70)$ \\
\hline \multicolumn{4}{|l|}{ Grading } \\
\hline G1 & $2(8.70)$ & $2(8.70)$ & $4(17.4)$ \\
\hline G2 & $5(21.7)$ & $10(43.4)$ & $15(65.2)$ \\
\hline G3 & $2(8.70)$ & $2(8.70)$ & $4(17.4)$ \\
\hline G4 & 0 & 0 & 0 \\
\hline \multicolumn{4}{|l|}{ UICC classification } \\
\hline I & 0 & $1(4.30)$ & $1(4.30)$ \\
\hline II & $7(30.4)$ & $8(34.8)$ & $15(65.1)$ \\
\hline III & $1(4.30)$ & $4(17.4)$ & $5(21.7)$ \\
\hline IV & $1(4.30)$ & $1(4.30)$ & $2(8.70)$ \\
\hline
\end{tabular}

were cut into fragments of $166 \mathrm{bp}$. The product of the second round PCR was subjected again to TspRI digestion, followed by electrophoretic analysis in a polyacrylamide gel.

PCR-SSCP analysis and sequencing of the B-Raf V599E mutation. The fragment encompassing exon 15 was amplified by PCR. Primer sequences and PCR conditions were previously published (7). Single-strand conformation polymorphism (SSCP) analysis was performed. Samples showing an altered mobility pattern were then subjected to sequencing analysis by the ABI PRISM dye terminator cycle sequencing reaction kit (Applied Biosystems, Foster City, CA) in an ABI 310 genetic analyzer.

PCR-SSCP analysis of the p53 gene in exons 4-9. To detect p53 mutations, a previously optimized PCR-SSCP method was applied (18). PCR reactions (MJ Research and Techne Cyclogen thermal cyclers) were conducted in a total volume of $25 \mu \mathrm{l}$ containing $150 \mathrm{ng}$ of template DNA, 1X PCR buffer, $1.75 \mathrm{mM} \mathrm{MgCl}_{2}, 0.2 \mathrm{mM}$ of each dNTP, $2.5 \mathrm{pmol}$ of each primer and 0.5 units of Taq DNA polymerase. The primers used for amplification were used as described by Deng et al (19) (Table I). The cycling reactions included 34 cycles of denaturation at $94^{\circ} \mathrm{C}$ for $30 \mathrm{sec}$ (first cycle, $5 \mathrm{~min}$ ), annealing at the appropriate temperature (exon $4,64^{\circ} \mathrm{C}$; exon $5,59^{\circ} \mathrm{C}$ and exons $6-9,63^{\circ} \mathrm{C}$ ) for $30 \mathrm{sec}$ and elongation at $72^{\circ} \mathrm{C}$ for $30 \mathrm{sec}$ (last cycle, $5 \mathrm{~min}$ ).

The amplified products were denatured in $95 \%$ formamide, $0.01 \mathrm{~N} \mathrm{NaOH}(1: 1.4)$ at $95^{\circ} \mathrm{C}$ for $10 \mathrm{~min}$ and analyzed on native polyacrylamide gels (12-18\% depending on the studied exons) at $15-17 \mathrm{~mA}, 4^{\circ} \mathrm{C}, 16-21 \mathrm{~h}$ in $1 \mathrm{X}$ TBE buffer. A modified silver staining method was applied for visualization. Briefly, the gels were soaked in 50\% methanol for $1 \mathrm{~h}$, then transferred to an ammonium-silver solution, containing $0.02 \mathrm{~N}$ $\mathrm{NaOH}, 0.375 \% \mathrm{NH}_{4} \mathrm{OH}, 0.8 \% \mathrm{AgNO}_{3}$ for $15 \mathrm{~min}$ and washed with $500 \mathrm{ml} \mathrm{dH_{2 }} \mathrm{O}$ for $10 \mathrm{~min}$. The staining reaction was developed with the use of $0.01 \%$ citric acid, $0.035 \%$ formaldehyde and the gels were fixed in $0.5 \%$ acetic acid. Staining reactions were promoted by gentle shaking.

Sequencing analysis. Amplified products with p53 mutations were purified (GFX PCR DNA and Gel Band Purification 
Kit, Amersham Biosciences) and sequenced on an ABI Prism $^{\mathrm{TM}} 310$ fluorescent sequencing analyzer (DYEnamic ${ }^{\mathrm{TM}}$ ET Terminator Cycle Sequencing Kit, Amersham Biosciences) following the manufacturer's instructions.

The detection of CMAP $m R N A$. The detection of CMAP mRNA was performed under multiplex PCR conditions. cDNA was synthesized with Sensiscript Reverse Transcriptase (Qiagen, Hilden, Germany) using poly-dT primers. An aliquot of the reverse transcription mixture served as a template for the PCR which contained the oligonucleotide primers for CMAP and GAPDH (Table I). GAPDH was used as an internal control. The PCR (35 cycles) generated fragments of 198 (CMAP) and $110 \mathrm{bp}$ (GAPDH). The final PCR product was run on a polyacrylamide gel, stained with ethidium bromide and analyzed under UV-light by videodensitometry. The levels of CMAP RNA were determined relative to those of GAPDH.

The primer concentrations for GAPDH (40, 20, 10 and $5 \mathrm{nM}$ ) and CMAP (200 nM) were chosen to yield similar amounts of template, as was found at the $20 \mathrm{nM} \mathrm{GAPDH}$ primer concentration in HL-60 cells, which were used as a control. The CMAP RNA level was considered to be increased if the template amounts were leveled at GAPDH primer concentrations $>20 \mathrm{nM}$.

Western blotting. The deregulation of the kinase activity of the B-Raf mutants was assessed using a phospho-specific ERK antibody (Santa Cruz Biotechnology). Tissues were homogenized with a homogenisator in lysis buffer [0.1 M $\mathrm{NaCl}, 25$ mM Tris-HCl (pH 8) 0.001 M EDTA (pH 8), 25\% glycerol and $10 \%$ ß-mercaptoethanol], containing complete protease inhibitor cocktail. Loading buffer (6X SDS) was added. Lysates were boiled for $8 \mathrm{~min}$ in a water bath at $100^{\circ} \mathrm{C}$ and centrifuged at 13,000 rpm at room temperature. Cell lysates were loaded on $10 \%$ PAA gels, transferred to a PVDF membrane, blocked in skimmed milk in PBS and incubated with a goat polyclonal antibody against pERK (Santa Cruz Biotechnology, Santa Cruz, CA). After washing in PBS containing Tween-20 (0.05\%), a secondary donkey anti-goat HRP antibody (Santa Cruz Biotechnology) was used as well as ECL (Santa Cruz Biotechnology).

Statistical analysis. The mean age of patients and the respective standard deviation was calculated for all subgroups. In addition, the non-parametric Wilcoxon test was used to compare the age of the respective subgroups. The contingency $\chi^{2}$ test was applied to compare all other patient and tumor characteristics. P-values $<0.05$ were regarded as significant.

\section{Results}

The characteristics of 23 patients with colorectal carcinoma are given in Table II. The mean age of the female patients (61.5 years) did not differ significantly from that of the males (63.2 years).

Within the large bowel, the majority of tumors were found in the rectum $(65.1 \%)$, followed by the sigmoid $(13.0 \%)$, the ascending colon $(13.0 \%)$ and the lowest numbers were detected in the transverse $(4.3 \%)$ and descending colon $(4.3 \%)$.
The majority of carcinomas were classified as T4 stage $(69.6 \%)$. As assessed by histology, $69.6 \%$ of all tumors did not show tumor dissemination in the regional lymph nodes (N0). In addition, $17.4 \%$ were ranked in the nodal status $\mathrm{N} 1$ and $13.0 \%$ in the N2. Clinical metastasis (M1) was found in $8.7 \%$. According to the UICC status, the highest percentage of patients was ranked as grade II $(65.1 \%)$, followed by grades III $(21.7 \%)$, IV $(8.7 \%)$ and I $(4.3 \%)$. There was no significant gender difference.

$K$-ras mutations, $B$-raf mutations and pERK status. The distribution of tumors within the colorectum relative to their mutation status is shown in Table III. Of the 23 tumors, 8 (39.1\%) were mutated in K-ras codons 12 or $13,7(30.43 \%)$ were mutated in codon 12 , and 1 in codon $13(4.3 \%)$. As expected, the mucosa and liver showed distinctly fewer genetic alterations. Two patients had a codon 12 and one a codon 13 mutation of the mucosa, one patient had a codon 12 mutation in the liver. Two out of 23 patients had a B-raf (V599) mutation in their tumor $(8.7 \%)$, but none were mutated in the mucosa or liver (Table III). In addition, 11 out of 22 tumors (50\%) were positive for pERK indicating the activation of the RAS/ RAF/ERK signaling cascade (Table III).

p53 mutations and CMAP levels. To detect the p53 mutations PCR-SSCP analysis was performed in exons 4-9 of the gene. Mutations in p53 were found in 6 patients $(6 / 23,26 \%)$. The patterns of aberrant electrophoretic mobility corresponded to p53 exons 4, 5, 7, 8 and 9 (Fig. 1a-d). In exon 9, two different mutational patterns were found in 2 different cases. In the liver and mucosa DNA, alteration in the electrophoretic mobility was found only in one patient. The aberration corresponded to exon 9 and was identical with the aberration found in tumor DNA. No mutations were found in exon 6 of the p53 gene.

Sequence analysis revealed two mis-sense substitutions (one of which was coupled with intronic polymorphism), one non-sense mutation, one deletion resulting in frameshift, three cases of intron 9 polymorphism and one polymorphism in intron 6 (see Table IV). The two mis-sense substitutions mapped to codons 151 and 248. The first represented a base substitution $(\mathrm{C}>\mathrm{G})$, which causes an amino acid substitution of Pro with Arg at position 151 (Fig. 2).

Out of 23 tumors, 13 showed an increased CMAP level (65.5\%, for example see Fig. 3). A preliminary follow-up showed that 10 of these patients have died since their surgery and two developed liver metastasis.

There was a significant correlation between ERK activation (presence of pERK) and a K-ras codon 12 mutation ( $\mathrm{p}=0.016)$, but there was no such correlation between the K-ras codon 13 and B-raf mutations with Erk activation.

All mutations found by PCR RFLP or SSCP in K-ras, B-raf and p53 genes were verified by sequencing (Table IV). The predominant K-ras alteration (8 out of 12 ) was a G:C to A:T transition mutation, resulting in an exchange of glycine to asparagine. The remaining four alterations were $\mathrm{G}: \mathrm{C}$ to $\mathrm{T}: \mathrm{A}$ and $\mathrm{G}: \mathrm{C}$ to $\mathrm{C}: \mathrm{G}$ transversion mutations. For the B-raf gene, the T:A to A:T transversion mutation was the only alteration detected. The 9 p53 mutations were more heterogeneous as shown by the presence of four T:A to $\mathrm{C}: \mathrm{G}$ and one $\mathrm{A}: \mathrm{T}$ to 
Table III. Frequency of the K-ras, B-raf, p53 mutations and presence of pERK and CMAPa in tissues of CRC patients.

\begin{tabular}{llcccccc}
\hline Tissue & \multicolumn{1}{c}{ Marker } & No. of samples & $(\%)$ & No. & (\%) Positive & No. & $(\%)$ Negative \\
\hline Tumor & K-ras codon 12 mutation & 23 & $(100)$ & 7 & $(30)$ & 15 & $(65)$ \\
& K-ras codon 13 mutation & 23 & $(100)$ & 1 & $(4.3)$ & 22 & $(95.6)$ \\
& B-raf mutation & 23 & $(100)$ & 2 & $(8.7)$ & 21 & $(81.6)$ \\
& pERK & 22 & $(100)$ & 11 & $(50)$ & 11 & $(50)$ \\
& p53 mutation & 23 & $(100)$ & 6 & $(26)$ & 17 & $(74)$ \\
& CMAP & 23 & $(100)$ & 13 & $(56.5)^{b}$ & 10 & $(43.5)$ \\
Mucosa & K-ras codon 12 mutation & 23 & $(100)$ & 2 & $(8.7)$ & 21 & $(91.5)$ \\
& K-ras codon 13 mutation & 23 & $(100)$ & 1 & $(4.3)$ & 22 & $(95.6)$ \\
& B-raf mutation & 23 & $(100)$ & 0 & $(0)$ & 23 & $(100)$ \\
Liver & p53 mutation & 23 & $(100)$ & 1 & $(4.3)$ & 22 & $(95.6)$ \\
& K-Ras codon 12 mutation & 23 & $(100)$ & 1 & $(4.3)$ & 22 & $(95.6)$ \\
& K-Ras codon 13 mutation & 23 & $(100)$ & 0 & $(0)$ & 23 & $(100)$ \\
& B-Raf mutation & 23 & $(100)$ & 0 & $(0)$ & 23 & $(100)$ \\
& p53 mutation & 23 & $(100)$ & 1 & $(4.3)$ & $(95.6)$ \\
\hline
\end{tabular}

${ }^{\mathrm{a} C M A P}$, cystatin-like metastasis-associated protein. ${ }^{\mathrm{b}}$ Samples with increased CMAP level ( $\geq 1.5$-fold).

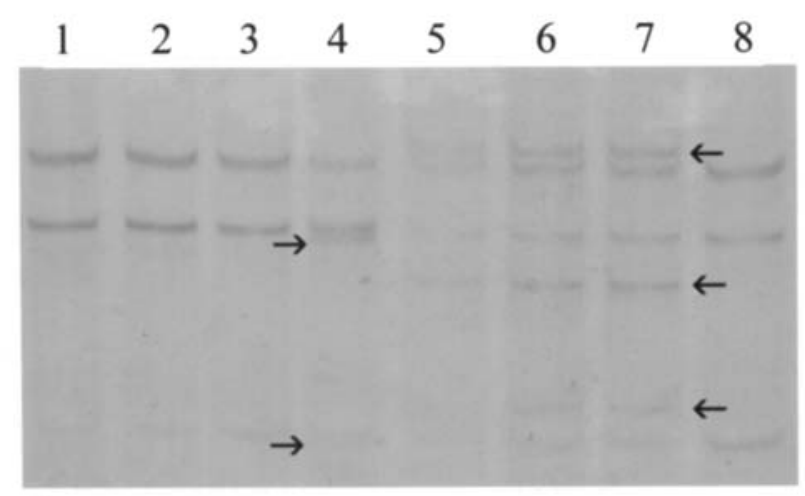

a

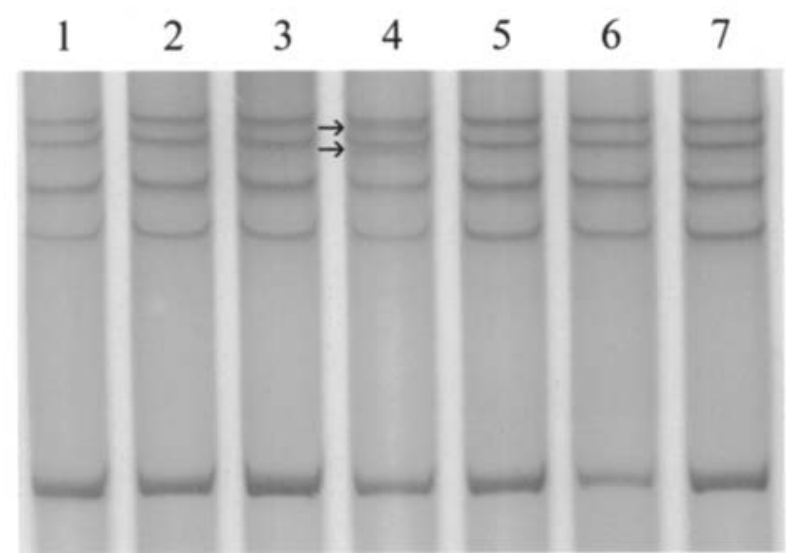

C

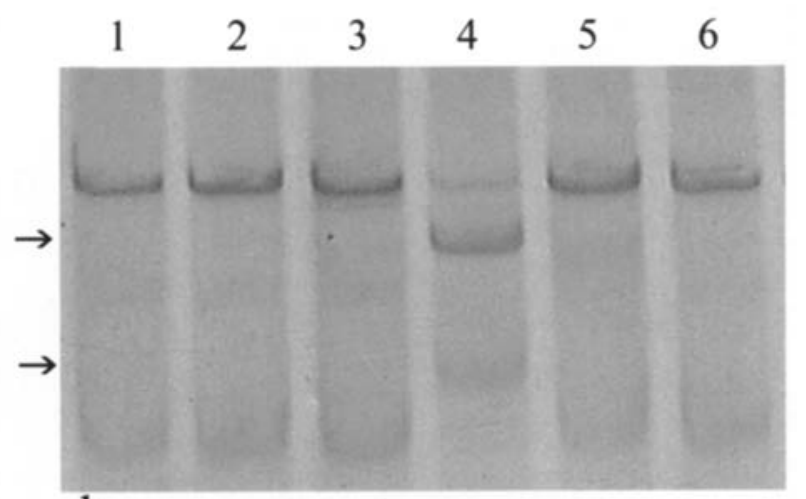

b

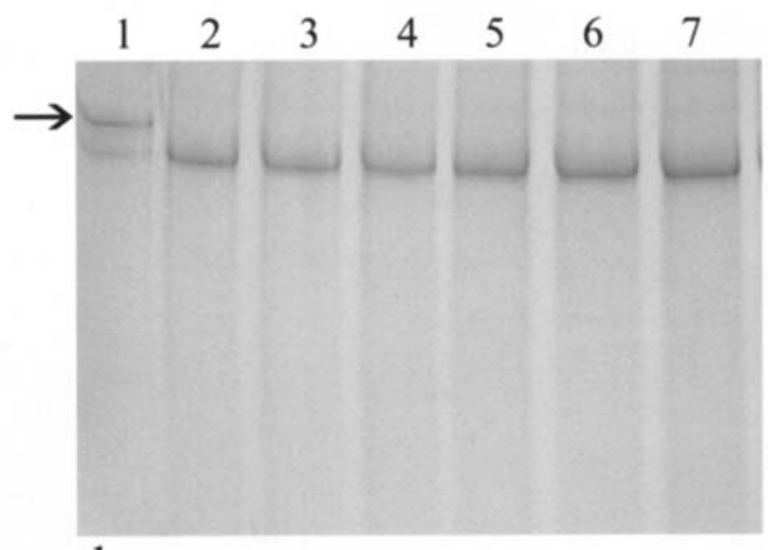

d

Figure 1. (a) PCR-SSCP analysis of exon 9 of the p53 gene; lane 4, mutation in tumor DNA of patient no. 1; lane 5, mutation in mucosa DNA of patient no. 9; lane 6, mutation in liver DNA of patient no. 9; lane 7, mutation in the tumor DNA of patient no. 9; lanes 1, 2, 3 and 8, patients with a normal pattern. (b) PCRSSCP analysis of exon 8 of the p53 gene; lane 4, mutation in the tumor DNA of patient no. 16; lanes 1, 2, 3, 5 and 6, patients with a normal pattern. (c) PCRSSCP analysis of exon 7 of the p53 gene; lane 4, mutation in the tumor DNA of patient no. 12; lanes 1, 2, 3, 5, 6 and 7, patients with a normal pattern. (d) PCRSSCP analysis of exon 5 of the p53 gene; lane 1, mutation in the tumor DNA of patient no. 4; lanes 2, 3, 4, 5, 6 and 7, patients with a normal pattern. Extra shift bands are marked with arrows. 


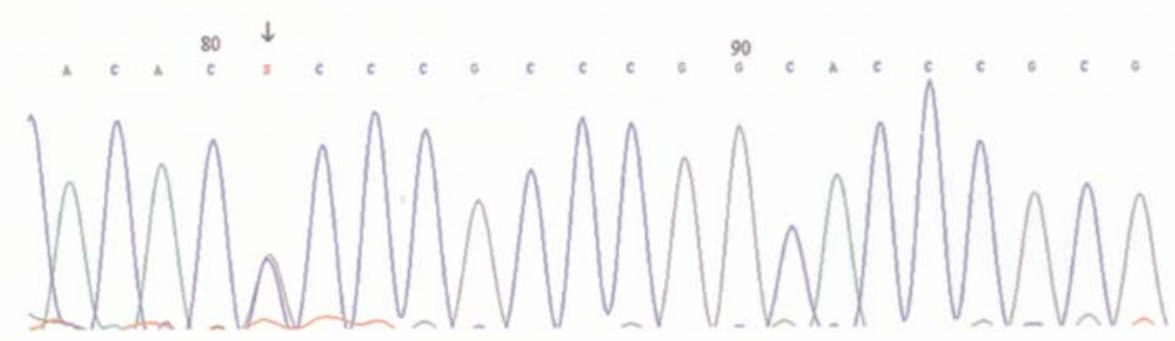

Figure 2. Sequence analysis with the forward primer of a sample with a mutant pattern in exon 5 of the p53 gene, C>G, p.Pro151Arg.

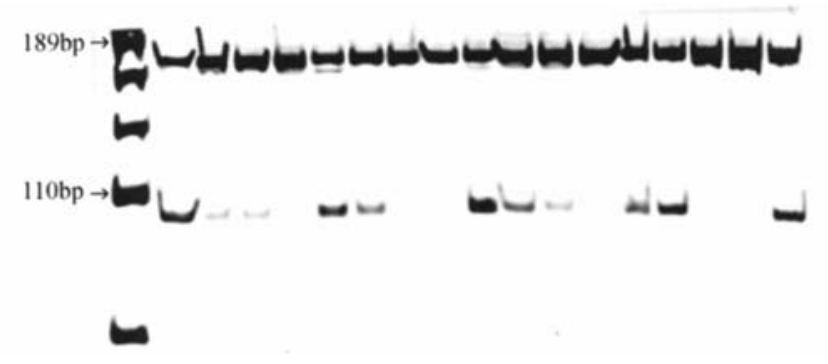

Figure 3. A multiplex RT-PCR of CMAP expression. The upper panel (198 bp) corresponds to CMAP expression and the lower panel (110 bp) corresponds to the GAPDH expression. The primer concentration of CMAP remained constant $(200 \mu \mathrm{M})$ whereas that of GAPDH varied from 40 (lanes 1, 5, 9 and 13) to $20 \mu \mathrm{M}$ (lanes 2, 6, 10 and 14), $10 \mu \mathrm{M}$ (lanes 3, 7, 11 and 15) and $5 \mu \mathrm{M}$ (lanes $4,8,12$ and 16). The lane to the right is the HL-60 control RNA with a GAPDH primer concentration of $20 \mu \mathrm{M}$.
$\mathrm{G}: \mathrm{C}$ transversion mutations, a deletion and two $\mathrm{C}: \mathrm{G}$ to $\mathrm{G}: \mathrm{C}$ and $\mathrm{G}: \mathrm{C}$ to $\mathrm{C}: \mathrm{G}$ transversion mutations (for example see Fig. 2).

\section{Discussion}

The aim of this study was to compare a panel of markers in samples of colorectal carcinoma for their suitability as predictors of prognosis. The markers were chosen to represent a whole signal cascade (RAS/RAF/ERK), as well as to supplement each other for their independent prognostic value (p53 and CMAP). For their importance in the same signaling cascade we assumed that K-ras codons 12 and 13 as well as B-raf mutations would all result in ERK phosphorylation. However, this was true only for K-ras codon 12 mutations, not for K-ras codon 13 and B-raf mutations. This unexpected

Table IV. The sequence analysis of the K-Ras, B-Raf and p53 mutations.

\begin{tabular}{|c|c|c|c|c|c|c|}
\hline Gene & $\begin{array}{l}\text { Patient no./ } \\
\text { tissue }\end{array}$ & $\begin{array}{l}\text { Codon } \\
\text { (exon) }\end{array}$ & $\mathrm{Wt}$ & $\begin{array}{l}\text { Mutated } \\
\text { sequence }\end{array}$ & $\begin{array}{l}\text { Amino acid } \\
\text { change }\end{array}$ & Mutation type \\
\hline \multirow[t]{12}{*}{ K-ras } & 4/tumor & 12 & GGT & GAT & Gly-Asp & mis-sense \\
\hline & 4/liver & 12 & GGT & GAT & Gly-Asp & mis-sense \\
\hline & 11/tumor & 12 & GGT & TGT & Gly-Cys & mis-sense \\
\hline & 14/tumor & 12 & GGT & GAT & Gly-Asp & mis-sense \\
\hline & 14/mucosa & 12 & GGT & GAT & Gly-Asp & mis-sense \\
\hline & 16/tumor & 12 & GGT & GAT & Gly-Asp & mis-sense \\
\hline & 16/mucosa & 12 & GGT & GAT & Gly-Asp & mis-sense \\
\hline & 17/tumor & 12 & GGT & GCT & Gly-Ala & mis-sense \\
\hline & 19/tumor & 12 & GGT & GTT & Gly-Val & mis-sense \\
\hline & 21/tumor & 12 & GGT & GCT & Gly-Ala & mis-sense \\
\hline & 22/tumor & 13 & GGC & GAC & Gly-Asp & mis-sense \\
\hline & 22/mucosa & 13 & GGC & GAC & Gly-Asp & mis-sense \\
\hline \multirow[t]{2}{*}{ B-raf } & 5/tumor & 600 & GTG & GAG & Val-Glu & mis-sense \\
\hline & 8/tumor & 600 & GTG & GAG & Val-Glu & mis-sense \\
\hline \multirow[t]{9}{*}{ p-53 } & 1/tumor & $331(9)$ & $\mathrm{CAG}$ & UAG & Gln-STOP & non-sense \\
\hline & 9/tumor & 14766 bp (intron 9) & $\mathrm{T}$ & $\mathrm{C}$ & & intron polymorphism \\
\hline & 9/liver & 14766 bp (intron 9) & $\mathrm{T}$ & $\mathrm{C}$ & & intron polymorphism \\
\hline & 9/mucosa & 14767 bp (intron 9) & $\mathrm{T}$ & $\mathrm{C}$ & & intron polymorphism \\
\hline & 16/tumor & $267(8)$ & CGG & c.800delG & & frameshift \\
\hline & $12 /$ tumor & $248(7)$ & CGG & $\mathrm{CGC}$ & Arg-Trp & mis-sense \\
\hline & & 13991 bp (intron 6) & A & $\mathrm{G}$ & & intron polymorphism \\
\hline & 4/tumor & $151(5)$ & $\mathrm{CCC}$ & CGC & Pro-Arg & mis-sense \\
\hline & 22/tumor & 12301 bp (intron 4) & $\mathrm{T}$ & $\mathrm{C}$ & & intron polymorphism \\
\hline
\end{tabular}


finding could be due to either the low number of K-ras codon 13 or B-raf mutations observed, or to the fact that these mutations have a lower impact on the whole tumor, thus resulting in less ERK phosphorylation which was missed when a lysate from the total tumor was used. The latter assumption is related to our previous observation that K-ras codon 12 and 13 mutations arise in comparable frequencies in mucosa tissues but that K-Ras codon 12 mutations prevail over codon 13 mutations in polyps, carcinomas and liver metastasis with a growing imbalance (20).

On the other hand, p53 and CMAP were chosen, since it was reported that p53 mutations indicate pathways for cell transformation alternative from the K-Ras cascade (21). p53 is an established marker for tumor progression in colorectal cancer development (22).

According to the available p53 databases (http://p53.free.fr) the substitution p.Pro151Arg was found in 14 cases of human carcinoma (2 colorectal carcinomas). The mutation affects the DNA binding domain of the p53 protein and based on the SIFT-value calculation is predicted to be deleterious (http://p53.free.fr). The other mis-sense substitution (c.742C $>\mathrm{T}$ ) mapped to the amino acid position 248 and was responsible for the amino acid change of 248Arg with Trp. Database analysis revealed that codon 248 is a p53 mutation hot-spot. Thus far, 1544 mutations are registered at that position. The mutation p.Arg248Trp (CGG-UGG) was also found in 625 cases of cancer, predominantly that of colorectal cancer (155 cases). The mis-sense mutation affects the DNA binding domain of the $\mathrm{p} 53$ protein and is predicted to be deleterious. The substitution was coupled with an A-G intron-6 polymorphism at position $13991 \mathrm{bp}$. Until now the same polymorphism was found only in one Bulgarian patient with breast cancer, again coupled with a mis-sense mutation but at position 245 (unpublished data).

A non-sense mutation was found in codon 331 and corresponded to a base substitution (C-T) which leads to the STOP codon UAG. The mutation concerns the oligomerization domain and truncates the p53 protein. The same substitution c.991C > T (p.Gln331X) has been registered in 19 cases of which 9 are breast cancer. The deletion was mapped to codon 267 (c.800delG) and results in a frameshift. It is generally assumed that non-sense and frameshift mutations are deleterious for $\mathrm{p} 53$.

The three T-C intron 9 polymorphisms were mapped at position 14766, 12 bp downstream of the $3^{\prime}$ end of exon 9. The polymorphism was previously reported in two healthy Italian blood donors (23), in three Bulgarian patients with Balkan Endemic Nephropathy (24) and in six Bulgarian patients with breast cancer (unpublished data). The other intronic polymorphism was located at position $12301 \mathrm{bp}$. Polymorphism affects the conservative thymine, mapping $2 \mathrm{bp}$ downstream of the $3^{\prime}$ end of exon 4 , which may have a potential impact on the splicing mechanism. Such a T12301C polymorphism has yet to be reported. According to the p53 mutation databases (http://www-p53.iarc.fr) there are 35 cases of p53 intronic polymorphisms registered thus far. It has been suggested that introns may play a significant role in the regulation of the gene expression and may function as nonsense, mis-sense and splice-site mutations. However, their correlation with the cancer phenotype has not been defined. p53 was the first tumor suppressor gene found to be mutated in human cancers. There are hundreds of studies devoted to understanding the function of the gene. The interest towards p53 is predetermined by the fact that the biochemical pathways, in which it is engaged, are the linkage between the environmental mutagens and the tightly regulated mechanisms which control cell growth and division. The p53 gene was identified 26 years ago. Ten years were needed to classify it as a tumor suppressor gene. The first p53 mutations were found in 1989. Fifteen years later the number of p53 mutations found in human carcinomas accounts for 14,000. It has been suggested that p53 is a kind of evolutionary mechanism which originated in higher organisms as a specific defense towards cancer (25). The main mechanism underlying the p53 function is the regulation of cell cycle checkpoints by blocking the cell cycle or by cell death carried out through apoptosis.

p53 mutations were found in $>50 \%$ of human tumors of the colon, stomach, liver, lung, breast, brain and others. Exons 4-8 of the p53 gene encode a highly conserved region, containing the DNA binding domain of the protein and most of the p53 mutations were found within that region. At least six mutation hot-spots corresponding to codons 175, 245, 248, 249, 273 and 282 have been identified in a variety of neoplasms. The relatively low percentage of unusual p53 mutations found in this study is surprising and may indicate a difference in the induction of colorectal cancer in Bulgaria as compared to other countries.

CMAP was only recently identified as a novel metastasisassociated gene. The gene for the human CMAP (ABO29636) possesses four individual exons, scattered over an $11 \mathrm{~kb}$ length, which encode the functional domains of the putative translational product (26). The protein, coded by this gene was named CMAP and showed a 22.1-28.1\% homology to human family II cystatins. Cysteine proteinases, such as cathepsin $\mathrm{B}, \mathrm{H}$ and $\mathrm{L}$, are regulated by endogeneous cysteine proteinase inhibitors named cystatins. One of the most important roles proposed for cathepsins and cystatins in tumor cell invasion is the degradation and remodelling of extracellular matrix (ECM) and therefore their levels may have clinical relevance as prognostic factors for cancer patients. In this study, 13 out of 23 patients showed increased levels of CMAP (>1.5-fold), 10 of whom have died since and 2 have developed liver metastasis. Although our investigations were done on a relatively small group of patients, the data show close correlations between the tumor expression levels of CMAP and liver metastasis for human colorectal cancer, as has been reported by Utsunomiya et al (16). According to our data CMAP can be used as a relevant early marker for tumor progression and liver metastasis.

The precise function of CMAP in patient prognosis remains unclear. However, the production levels of the cysteine proteinase inhibitor may possibly increase to compensate for an excessively induced cysteine proteinase in metastatic tumor cells, and as a result an imbalance may occur between the cysteine proteinase and its inhibitor, which seems to play an important role in tumor invasion and metastasis (16). The expression of mCMAP was first detected in lymphoid organs, such as the thymus, spleen and lymph nodes. This unique distribution of mCMAP in lymphoid organs 
suggests its physiological association with the immune system (15).

When combining all markers used, it can be concluded that the incidence of positive findings indicating mutations of potential marker genes for tumor progression and metastasis rose with the tumor stage: No sample was positive in T1 tumors, 1 in T2 tumors (50\%), 3 in T3 tumors (75\%), but 23 in $16 \mathrm{~T} 4$ tumors. This is a significant correlation of the positive markers with tumor stage (trend test, $\mathrm{p}=0.001$ ). In this way, the current observations involving the three markers of the RAS/ERK signal cascade which are important for mitogenesis, and the two markers which have an independent prognostic value is an extension of our previous study in which we studied three markers in colorectal cancer patients (27). A follow-up of the study patients will be necessary to compare the assumptions generated from the frequency of positive markers with patient outcome. The data will also have to be validated by a larger database before definitive conclusions can be drawn.

In summary, in this group of advanced colorectal cancer patients, there was a significant correlation between ERK activation and a concomitant $\mathrm{K}$-ras codon 12 mutation ( $\mathrm{p}=0.016$ ), but not between K-ras codon 13 or B-raf mutations and Erk activation. The finding that the vast majority of patients with increased CMAP levels had very short survival or developed liver metastasis needs further scrutiny. p53 alterations included non-sense $(n=1)$, mis-sense $(n=2)$ and frameshift mutations $(n=1)$ as well as intron polymorphisms $(n=5)$ and thus showed a low frequency and an unusual profile of alterations. The sum of positive findings of the markers used was related to the individual tumor stage.

\section{Acknowledgements}

The short-term fellowships for Dr Milka Georgieva from the German Cancer Research Center and from UICC are gratefully acknowledged.

\section{References}

1. Graziano F and Cascinu S: Prognostic molecular markers for planning adjuvant chemotherapy trials in Dukes' B colorectal cancer patients: how much evidence is enough? Ann Oncol 14: 1026-1038, 2003.

2. McLeod HL, Murray GI, Mollison J, McKay J and Cassidy J: Selection of markers to predict tumour response or survival: description of a novel approach. Eur J Cancer 35: 1650-1652, 1999.

3. Jass JR, Whitehall VL and Leggett BA: Emerging concepts in colorectal neoplasia. Gastroenterology 123: 862-867, 2002.

4. Steegeng WT, van der Eb AJ and Jochensen AG: How phosphorylation regulates the activity of p53. J Mol Biol 263: 103$113,1999$.

5. Robinson MJ and Cobb MH: Mitogen-activated protein kinase pathways. Curr Opin Cell Biol 9: 180-186, 1997.

6. Malunders M and Barbacid M: Ras oncogenes: the first 30 years. Nat Rev Cancer 3: 459-465, 2003.

7. Davies H, Bignell GR, Cox C, Stephens P, Edkin S, Clegg S, Teague J, Woffendin H, Garnett MJ, Bottomley W, Davis N, Dicks E, Ewing R, Floyd Y, Gray K, Hall S, Hawes R, Hughes J, Kosmidou V, Menzies A, Mould C, Parker A, Stevens C, Watt S, Hooper S, Wilson R, Jayatilake H, Gusterson B, Cooper C, Shipley J, Hargrave D, Pritchard-Jones K, Maitland N, Chenevix-Trench G, Riggins GJ, Bigner D, Palmieri G, Cossu A, Flanagan A, Nicholson A, Ho JWC, Leung SY, Yuen ST, Weber B, Seigler HF, Darrow T, Peterson H, Marais R, Marshall CJ, Wooster R, Straton MR and Futreal PA: Mutations of the B-Raf gene in human cancer. Nature 417: 949-954, 2002.
8. Rajagopalan H, Bardelli A, Lengauer C, Kinzler KW, Vogelstein B and Velculescu VE: Tumorigenesis: RAF/RAS oncogenes and mismatch repair status. Nature 418: 934, 2002.

9. Singer G, Oldt R III, Cohen Y, Wang BG, Sidransky D, Kurman RJ and Shih I: Mutations in BRAF and KRAS characterize the development of low-grade ovarian serous carcinoma. J Natl Cancer Inst 95: 484-486, 2003.

10. Cohen Y, Goldenberg-Cohen N, Parrella P, Chowers I, Merbs SL, Peter $\mathrm{J}$ and Sidransky D: Lack of BRAF mutation in primary uveal melanoma. Invest Ophtalmol Vis Sci 44: 2876-2878, 2003.

11. Eliceiri BP, Klemke R, Strömblad S and Cheresh DA: Integrin $x \mathrm{v} ß 3$ requirement for sustained mitogen-activated protein kinase activity during angiogenesis. J Cell Biol 14: 1255-1263, 1998.

12. Bonni A, Brunet A, West AE, Datta SR, Takasu MA and Greenberg ME: Cell survival promoted by the Ras-MAPK signaling pathway by transcription-dependent and -independent mechanisms. Science 286: 1358-1362, 1999.

13. Mercer $\mathrm{K}$ and Pritchard CA: Raf proteins and cancer: B-Raf is identified as a mutational target. Biochim Biophys Acta 1653: 25A-40A, 2003.

14. Gonzales-Aguilera J, Oliart S, Azcoita MM and Fernandez-Peralta A: Simultaneous mutations in KRAS and TP53 are indicative of poor prognosis in sporadic colorectal cancer. Am J Clin Oncol 27: 39-45, 2004

15. Morita M, Yoshiuchi N, Arakawa H and Nishimura S: CMAP: a novel cystatin-like gene involved in liver metastasis. Cancer Res 59: 151-158, 1999.

16. Utsunomiya T, Hara Y, Kataoka A, Morita M, Arakawa H, Mori M and Nishimura S: Clin Cancer Res: 2591-2594, 2002.

17. Dieterle CP, Conzelmann M, Linnemann $U$ and Berger M: Detection of isolated tumor cells by polymerase chain reactionrestriction fragment length polymorphism for K-ras mutations in tissue samples of 199 colorectal cancer patients. Clin Cancer: 641-650, 2004.

18. Krasteva ME, Garanina Z and Georgieva EI: Optimized polymerase chain reaction-based single-strand conformation polymorphism analysis of p53 gene applied to Bulgarian patients with invasive breast cancer. Clin Exp Med 3: 173-180, 2003.

19. Deng G, Chen L-C, Schott DR, Thor A, Bhargava V, Ljung B-M, Chew $\mathrm{K}$ and Smith HS: Loss of heterozygosity and p53 gene mutations in breast cancer. Cancer Res 54: 499-505, 1999.

20. Kraus M, Seelig M, Linnemann U and Berger M: The balanced induction of K-Ras codon 12 and 13 mutations in mucosa differs from their ratio in neoplastic tissues. Int J Oncol 29: 957-964, 2006.

21. Calistri D, Rengucci C, Seymour J, Lattuneddu A, Polifemo A, Monti F, Saragoni L and Amadori D: Mutation analysis of p53, $\mathrm{K}-\mathrm{Ras}$ and B-Raf genes in colorectal cancer progression. J Cell Physiol 204: 484-488, 2005.

22. Fearon ER and Vogelstein B: A genetic model for colorectal tumorigenesis. Cell 61: 759-767, 1990.

23. Graziani D, Romagnoli S, Cassani B, Alfano RM, Roncalli M and Coggi G: An Ava I polymorphism in the TP53 gene. Mol Cell Probes 13: 393-395, 1999.

24. Krasteva ME and Georgieva EI: Germline p53 single-base changes associated with Balkan endemic nephropathy. Biochem Biophys Res Commun 342: 562-567, 2006.

25. Vousden KH and Lu X: Live or let die: the cell's response to p53. Nat Rev Cancer 2: 594-604, 2002.

26. Morita M, Hara Y, Tamai Y, Arakawa H and Nishimura S: Genomic construct and mapping of the gene for CMAP (Leukostatin/Cystatin F, CST7) and identification of a proximal novel gene BSCv (C20orf3). Genomics 67: 87-91, 2000.

27. Conzelmann M, Linnemann U and Berger MR: Molecular detection of clinical colorectal cancer metastasis: how should multiple markers be put to use? Int J Colorectal Dis 20: 137-146, 2005 . 